\title{
Determinación de las propiedades antioxidantes del Prunus armeniaca
} (damasco)

Miriam Palomino, Aníbal Pacheco, Christian Palomino, Rosa Oriondo, Justina Najarro

Facultad de Medicina UNMSM

Objetivos: Evaluar las propiedades antioxidantes del fruto de Prunus armeniaca L. (damasco). Determinar la capacidad antioxidante del fruto de damasco

Diseño: Descriptivo transversal

Institución: Centro de Investigación de Bioquímica y Nutrición, Facultad de Medicina, UNMSM y Departamento de Nutrición, Facultad de Medicina UNMSM.

Material biológico: Fruto de Prunus armeniaca L (damasco).

Intervenciones: Determinación del efecto antioxidante mediante la técnica DPPH. Grado de inhibición en un medio generador de radicales hidroxilo ascorbato/ Cu-II.

Principales medidas de resultados: 1) mg de vitamina C/ $100 \mathrm{~g}$ de muestra; 2) IC50; 3) generación de ROS en un sistema ascorbato /Cu-II.

Resultados: La fruta de damasco tuvo una concentración de $6 \mathrm{mg} \%$ de vitamina C. El damasco disminuyó en forma discreta la generación de radicales hidroxilo. El efecto inhibitorio que ejerció el damasco sobre los radicales hidroxilo generados por el sistema ascorbato/Cu-II dependió de la concentración de la fruta. Cuando se determinó la generación de radicales hidroxilo en función del tiempo, en un sistema ascorbato/Cu-II y damasco, se observó que la generación de ROS en presencia de esta fruta fue menor que el control. El porcentaje de captación de radicales libres fue $32 \%$.

Conclusiones: El damasco tuvo buena actividad antioxidante

Palabras clave: Damasco, antioxidante, radicales libres.

\section{Actividad antioxidante y gastroprotectora del extracto hidroalcohólico de hojas de Heliotropum arborescens L, en úlceras inducidas con etanol en estómago de ratas}

Miriam Palomino, Oscar Huamán, Elsa Béjar, Christian Palomino, Justina Najarro

Facultad de Medicina UNMSM

Objetivos: Evaluar la actividad antioxidante y protectora del extracto hidroalcohólico de Heliotropium arborescens $L$ 'cayaraja' sobre la mucosa gástrica en úlceras inducidas en ratas. Evaluar el efecto antioxidante. Evaluar el grado de protección del extracto en estómago de ratas

Diseño: Descriptivo transversal

Institución: Facultad de Medicina UNMSM.

Material biológico: 48 ratas machos y 30 ratones.

Intervenciones: Para evaluar el efecto protector se administró fármacos y extracto a 6 grupos: I control; II ranitidina; III sucralfato; IV, V y VI extracto 200, 400 y 600 mg/kg vía oral; luego, se realizó laparatomía abdominal y análisis bioquímico correspondiente.

Principales medidas de resultados: Marcha fitoquímica, IC50. Evaluación histopatológica del estómago: úlceras/ individuo. Análisis bioquímico: moco y GS-NP: mL/g de tejido.

Resultados: El extracto de cayaraja presentó efecto protector dosis dependiente. El tratamiento con ranitidina no produjo protección frente al etanol; el tratamiento con sucralfato produjo buen efecto citoprotector. Se observó gastritis erosiva en las ratas tratadas con extracto 200 y $400 \mathrm{mg} / \mathrm{kg}$; con $600 \mathrm{mg} / \mathrm{kg}$ y sucralfato no se presentaron erosiones gástricas. La actividad antioxidante IC50 del extracto fue 2,62.

Conclusiones: La cayaraja presentó actividad gastroprotectora y actividad antioxidante.

Palabras clave: Carayaja, extracto etanólico, úlcera del estómago, ratas. 